\title{
Identifying gaps in consumer health library collections: a retrospective review
}

\author{
Eleni Giannopoulos; Michelle Snow; Mollie Manley; Katie McEwan; Andrew Stechkevich; Meredith Elana Giuliani; Janet \\ Papadakos
}

See end of article for authors' affiliations.

\begin{abstract}
Background: The objective of this study was to determine if search request forms, which are used when a patron's request for information cannot be fulfilled at the time of contact with the library team, can be used to identify gaps in consumer health library collections.
\end{abstract}

\begin{abstract}
Case Presentation: Search request forms were collected from 2013 to 2020 and analyzed independently by two reviewers. Search request forms were included if they were complete and contained a record of how the request was fulfilled. Descriptive statistics were used to summarize patron characteristics. Search request forms were iteratively coded to identify themes in the data and determine if resources provided to patrons could be found within the library collection. The study team subsequently reviewed search request forms to determine reasons for identified gaps. Two hundred and forty-nine search request forms were analyzed. Six main content themes were identified: 1) understanding the cancer diagnosis, 2) cancer treatments, 3) understanding disease prognosis, 4) support during and after treatment, $5)$ natural health products and therapeutic effects in oncology, and 6) research literature. The majority of patrons were patients (53\%). Over half (60\%) of the submitted search request forms reflected collection gaps, and many (16\%) contained queries for information about rare cancer diagnoses. The main reason that queries could not be satisfied was that there was limited consumer health information on the requested topics (53\%).
\end{abstract}

Conclusions: Search request forms are a useful resource for assessing gaps in consumer health library collections.

Keywords: neoplasm; consumer health; gap analysis; collection development

\section{BACKGROUND}

Cancer patients and their families want to be well informed about their diagnosis throughout their cancer journey, regardless of prognosis [1, 2]. Provision of information has a wide range of benefits including improved understanding about disease, treatment, and methods of management [3-6]. Meeting cancer patients' informational needs can lead to lowered anxiety, improved coping, and overall health [7]. As cancer care continues to advance, consumer health libraries are challenged to consistently update and expand their collections to respond to the changing information needs of patient and family patrons $[8,9]$.

A growing body of evidence underscores the value of consumer health libraries. Consumer health libraries positively impact patient health and save time for health care providers who are readily able to access information about important topics such as side effect management, specific drugs, and clinical guidelines [10, 11]. Knowing more about their cancer and treatment options allows patients to exert greater control over their health [12], and patients who receive more information about treatment options are more active in health-related decision-making [13]. The value of health libraries is further acknowledged when we consider that information on the Internet is not regulated, and health information of varying relevance, quality, currency, and readability levels is widely accessible on the Internet to patients and families [14]. This can present a challenge for individuals who are unable to assess the credibility of online information or who may be subject to "information overload" [15]. This might be of particular importance to patients and families with low health literacy, for whom self-navigating through the Internet and locating reliable health information can be a significant challenge [14]. Consumer health libraries can intervene by providing individualized support to patients and families who seek information about cancer-related topics. In addition, consumer health libraries are consistently credited for providing more than just improved patient understanding or knowledge; they offer unique, individualized social support to cancer patients who may feel anxious, especially at the time of their diagnosis or prior to the start of treatment [16]. 
Furthermore, consumer health libraries can have a tremendous impact on patient safety and satisfaction [17].

Search request forms are specialized tools that contain several open- and closed-ended questions and are administered by a librarian to solicit detailed information about patrons' requests for information. The librarian completes the search for resources, and the search yield is emailed, sent by post, or picked up by the patron in person.

Here, we explored whether an archive of search request forms could be used to identify gaps in a library collection as an adjunct to more traditional collection development approaches. Our specific aims were to determine if search request forms could be used to 1) identify gaps in a library collection and 2) understand why these gaps exist.

\section{CASE PRESENTATION}

\section{Search request forms}

The consumer health library in Princess Margaret Cancer Centre, a large, urban and academic cancer center in Canada, has an extensive collection of vetted, high-quality cancer-related resources $[3,18]$. These resources are available in several different media formats including pamphlets, books, e-books, videos, and curated lists of reliable websites. A librarian is responsible for collection development and reviewing online and print resources to ensure that resources are able to address the needs of patrons. It is common protocol for the librarian to provide an information consult to locate resources within both the physical and virtual library collections for patient and family patrons [3]. Information consults are quick reference interviews to determine an individual's information needs, which is especially relevant considering that some information needs are explicit while some are implicit and may be more difficult for patrons to articulate [3]. In the event that the request for information cannot be fulfilled immediately because the information is not available in the library collection (e.g., research articles), the patron is constrained by time and cannot wait, or the query is complex and requires a further search online, a request for information can be made using a search request form.

An archive of search request forms collected from 2013 to 2020 was examined and independently reviewed by two reviewers. All collected search request forms were included if the section asking for "type of information requested" was complete and the form contained a record of how the request for information was fulfilled. The librarian attaches a print summary of the search yield to each completed search request form. The summary is formatted as a letter addressed to the patron and includes references and hyperlinks to the materials provided. Search request forms were excluded if the information requests were not related to cancer (e.g., information about ulcerative colitis) or were incomplete (e.g., fewer than three fields completed).

\section{Data analysis}

In order to analyze the contents of search request forms, data from each eligible form were entered into an Excel database [19]. Data included information about the patron (e.g., patient or family), cancer diagnosis, preferred method for receiving information (e.g., email), and purpose of the request (e.g., treatment-related, diagnosis). Once the data from the forms were entered, each search request was coded to document whether the request was a single request for information (e.g., seeking treatmentrelated information) or contained more than one request (e.g., seeking information about primary diagnosis, potential treatment options, and strategies for side effect management).

\section{Aim 1. Identification of collection gaps}

A study team member iteratively coded each search request form to explore themes in the requests using an inductive approach [20, 21]. For example, several search request forms included requests for basic information about uncommon cancers and were coded as "rare cancers." A second study team member reviewed the themes and discussed opportunities to refine them with two study team members until consensus was reached. A third study team member (i.e., the librarian) was consulted if any discrepancies or questions arose. Following thematic coding, study team members reviewed the search yield of each search request form to determine if the resources sent to the patron could be found within the physical or virtual library collection or if the request required a further search. Requests that could not be fulfilled by resources available in the library collection were deemed to be gaps.

Aim 2. Identification of reasons for collection gaps

Study team members reviewed themes from the search request forms to determine reasons for the identified gaps. Study team members discussed whether 1) there was limited consumer health information on the topic, 2) the information could not be accessed due to paywall restrictions or controlled membership, 3) the query was uncommon, or 4) there was abundant consumer health information but it did not meet health literacy best practices. Information that follows health literacy best practices is accurate, easy to understand, actionable, and accessible [22]. Limited consumer health information indicated topics for which there was limited information published, and controlled membership referred to resources that required subscriptions in order to access the information. 


\section{Library patron characteristics}

Between 2013 and 2020, 260 search request forms were submitted to the library. Duplicate requests were removed, and the remaining search request forms were reviewed against inclusion and exclusion criteria. Two hundred and forty-nine search request forms met inclusion criteria and were analyzed. The majority of patrons were patients (Table 1). The most commonly reported cancer diagnosis was breast cancer, followed by hematologic (e.g., central follicular lymphoma, marginal zone lymphoma) and gynecologic (e.g., ovarian cancer, cervical cancer) cancers. Most patrons indicated that they preferred information from the search request to be delivered via email. The majority of search requests contained multiple requests for information.

\section{Content categories in search requests}

Six main content themes were identified in the search request forms: 1 ) understanding the cancer diagnosis, 2) cancer treatments, 3) understanding disease prognosis, 4) support during and after treatment, 5) natural health products and therapeutic effects in oncology, and 6) research literature. The majority of search requests asked for information to help in understanding the cancer diagnosis (39\%), cancer treatments $(31 \%)$, and the cancer prognosis $(13 \%)$. Fewer search requests asked for research literature $(8 \%)$, information about support during and after treatment $(5 \%)$ and natural health products and therapeutic effects $(4 \%)$.

Queries regarding the cancer diagnosis included requests for information about cancer type (e.g., staging, pathology, and genetic factors), information about diagnostic testing and safety (e.g., magnetic resonance imaging (MRI) or computed tomography scanning), and multilingual health information about the cancer type (e.g., information in Chinese or Italian).

Treatment-related requests included queries for specific chemotherapy regimens (e.g., carboplatin), radiotherapies (e.g., proton therapy), targeted or hormonal therapies (e.g., tamoxifen), and immunotherapies (e.g., Revlimid). Additional treatment requests regarded side effects and their management (e.g., pain or fatigue) and treatment decisions (e.g., lumpectomy versus mastectomy).

Table 1 Search request form requester information $(n=249)$

\begin{tabular}{|c|c|c|}
\hline \multicolumn{2}{|l|}{ Patron information } & \multirow{2}{*}{$\begin{array}{l}\text { n (\%) } \\
132(62.9 \%)\end{array}$} \\
\hline Patron & Patient & \\
\hline & Family member & $56(22.5 \%)$ \\
\hline & Other (e.g., staff, friend, visitor) & $23(9.2 \%)$ \\
\hline & Unspecified & $38(15.3 \%)$ \\
\hline \multicolumn{3}{|l|}{ Cancer diagnosis } \\
\hline \multirow[t]{12}{*}{ Cancer type } & Breast & $58(23.3 \%)$ \\
\hline & Hematology & $41(16.5 \%)$ \\
\hline & Gynecology & $25(10.0 \%)$ \\
\hline & Gastrointestinal & $23(9.2 \%)$ \\
\hline & Genitourinary & $22(8.8 \%)$ \\
\hline & Sarcoma & $21(8.4 \%)$ \\
\hline & Head and neck & $15(6.0 \%)$ \\
\hline & Unspecified & $12(4.8 \%)$ \\
\hline & Lung & $11(4.4 \%)$ \\
\hline & Other (e.g., neuroendocrine cancer) & $9(3.6 \%)$ \\
\hline & Melanoma & $7(2.8 \%)$ \\
\hline & Brain & $5(2.0 \%)$ \\
\hline \multicolumn{3}{|l|}{ Information delivery } \\
\hline \multirow[t]{4}{*}{ Method of delivery* } & Email & $173(69.5 \%)$ \\
\hline & Pick-up & $61(27.7 \%)$ \\
\hline & Mail & $19(9.2 \%)$ \\
\hline & Unspecified & $10(4.0 \%)$ \\
\hline \multirow[t]{2}{*}{ Type of request } & Multiple requests for information & $162(65.1 \%)$ \\
\hline & Single request for information & $87(34.9 \%)$ \\
\hline
\end{tabular}

*Some respondents selected more than one option 


\section{Resources provided to library patrons}

The librarian consulted several library resources (i.e., a combination of resources developed by external organizations as well as by the hospital) as well as research information to fulfill patrons' requests. The majority of sources provided to library patrons were found within the library collection and were developed by external organizations (i.e., Canadian Cancer Society, American Cancer Society, National Cancer Institute, and Mayo Clinic) [17]. Hospital-developed resources were also provided to patrons. External and hospital-developed resources included webpages, books, pamphlets, and videos. Additional resources consulted included published research articles (Figure 1).

\section{Identifying and explaining collection gaps}

Over half of the submitted search request forms reflected gaps in the library collection $(n=150,60 \%)$ (Table 2). Of these, the majority contained queries for information about rare cancer diagnoses (e.g., leiomyosarcoma and myelodysplastic syndrome) (17\%). Regarding cancer treatments, most search requests contained queries for information on reconstructive surgery $(4 \%)$, followed by treatment decisions related to breast reconstructive surgery (e.g., saline vs. silicone implants) (3\%). The top queries related to understanding the cancer prognosis were about treatment-related survival and quality of life (5\%) and chances of metastasis (5\%). Regarding support during and after treatment, most search requests asked for information about support groups (e.g., locations and types of groups) (3\%). Most queries for information about natural health products and therapeutic effects in oncology were about medical cannabis (4\%).

The main reason queries could not be satisfied at the time of the information consult was there was limited consumer health information on the requested topics (53\%). This was the case for all topics related to understanding the cancer diagnosis, cancer treatments, and natural health products and therapeutic effects in oncology. A large proportion of queries contained topics that were not accessible due to paywall or membership restrictions $(25 \%)$, such as information about natural health products and therapeutic effects in oncology. For a small portion of queries, there was abundant consumer health information available that did not meet health literacy best practices $(14 \%)$ or the query was uncommon $(9 \%)$. This was the case for most queries related to understanding the disease prognosis. For example, one patron asked for information about lung cancer metastasis, including growth rates and patterns of spreading. Resources provided to satisfy this request included webpages and findings from the American Society of Clinical Oncology (ASCO), which consists of clinical guidelines, research, and some educational materials for patients and families [23, 24]. However, ASCO information regarding lung cancer metastases was intended for clinician use and, as such, did not meet health literacy best practices.

Figure 1 Resources provided to library patrons.

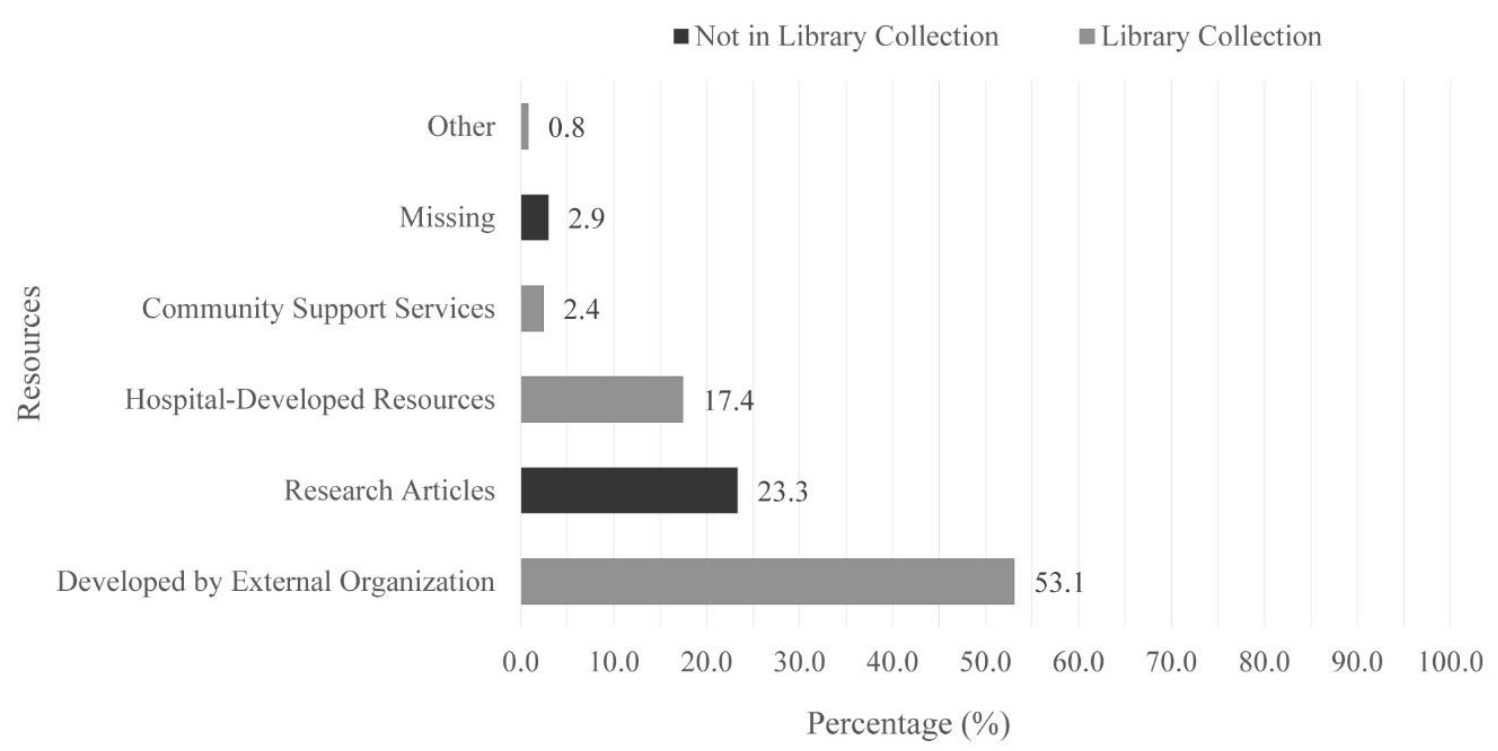


DOI: dx.doi.org/10.5195/jmla.2021.895

Table 2 Content gaps identified in search requests

\begin{tabular}{|c|c|c|c|c|c|c|}
\hline \multirow{2}{*}{$\begin{array}{l}\text { Content gap } \\
\text { categories }\end{array}$} & \multirow[t]{2}{*}{ Content gap subcategories } & \multirow[t]{2}{*}{ Frequency } & \multicolumn{4}{|c|}{ Reasons for gaps } \\
\hline & & & $\begin{array}{l}\text { Limited } \\
\text { consumer } \\
\text { health } \\
\text { information }\end{array}$ & $\begin{array}{l}\text { Access } \\
\text { controlled } \\
\text { membership }\end{array}$ & $\begin{array}{l}\text { Uncommon } \\
\text { query }\end{array}$ & $\begin{array}{l}\text { Abundant } \\
\text { consumer health } \\
\text { information that } \\
\text { does not meet } \\
\text { health literacy best } \\
\text { practices }\end{array}$ \\
\hline \multicolumn{7}{|c|}{ Understanding the cancer diagnosis } \\
\hline \multirow{3}{*}{$\begin{array}{l}\text { Learning about } \\
\text { cancer type }\end{array}$} & Rare cancer diagnosis & 25 & $x$ & & & \\
\hline & $\begin{array}{l}\text { Pathology (e.g., growth, } \\
\text { morphology) }\end{array}$ & 2 & $x$ & & $x$ & \\
\hline & $\begin{array}{l}\text { Environmental risks (e.g., radiation } \\
\text { exposure) }\end{array}$ & 5 & $x$ & & $x$ & \\
\hline \multirow[t]{2}{*}{$\begin{array}{l}\text { Diagnostic testing } \\
\text { and safety }\end{array}$} & $\begin{array}{l}\text { Visual inspection with acetic acid for } \\
\text { cervical cancer }\end{array}$ & 1 & $x$ & & $x$ & \\
\hline & $\begin{array}{l}\text { Gadolinium-based contrast agents } \\
\text { for MRI }\end{array}$ & 2 & $x$ & & $x$ & \\
\hline \multicolumn{7}{|l|}{ Cancer treatments } \\
\hline \multirow[t]{3}{*}{ Radiotherapy } & Integrated boost radiation & 1 & $x$ & & & \\
\hline & Targeted intraoperative therapy & 1 & $x$ & & & \\
\hline & Metabolically adaptive radiation & 1 & $x$ & & & \\
\hline \multirow[t]{2}{*}{ Surgery } & $\begin{array}{l}\text { Reconstructive surgery (e.g., breast } \\
\text { and cervical cancer) }\end{array}$ & 6 & $x$ & & & \\
\hline & $\begin{array}{l}\text { Amputation (e.g., preventing } \\
\text { sarcoma metastasis) }\end{array}$ & 1 & & & & $x$ \\
\hline \multirow{4}{*}{$\begin{array}{l}\text { Side effects of } \\
\text { treatment }\end{array}$} & Dental issues (e.g., tooth sensitivity) & 1 & $x$ & & & \\
\hline & Vision loss & 1 & $x$ & & & \\
\hline & $\begin{array}{l}\text { Gynecologic problems (e.g., vaginal } \\
\text { discharge) }\end{array}$ & 1 & $x$ & & & \\
\hline & Axillary web syndrome & 1 & $x$ & & & \\
\hline \multirow{6}{*}{$\begin{array}{l}\text { Treatment } \\
\text { decisions: breast } \\
\text { cancer }\end{array}$} & $\begin{array}{l}\text { Tamoxifen vs. aromatase inhibitors } \\
\text { (e.g., Letrozole) }\end{array}$ & 4 & $x$ & & & \\
\hline & Tamoxifen vs. radiotherapy & 1 & $x$ & & & \\
\hline & Lumpectomy vs. mastectomy & 3 & $x$ & & & \\
\hline & $\begin{array}{l}\text { Breast reconstructive surgery; saline } \\
\text { vs. silicone }\end{array}$ & 5 & $x$ & & & \\
\hline & $\begin{array}{l}\text { Cyclophosphamide vs. docetaxel } \\
\text { chemotherapy }\end{array}$ & 1 & $x$ & & & \\
\hline & Hormonal therapy vs. radiotherapy & 1 & $x$ & & & \\
\hline \multirow{2}{*}{$\begin{array}{l}\text { Treatment } \\
\text { decisions: ovarian } \\
\text { cancer }\end{array}$} & $\begin{array}{l}\text { Radical hysterectomy vs. fertility- } \\
\text { saving treatment }\end{array}$ & 2 & $x$ & & & \\
\hline & Surgery vs. chemotherapy & 1 & $x$ & & & \\
\hline $\begin{array}{l}\text { Treatment } \\
\text { decisions: lung } \\
\text { cancer }\end{array}$ & $\begin{array}{l}\text { Lobectomy vs. segmentectomy or } \\
\text { pneumonectomy }\end{array}$ & 1 & $x$ & & & \\
\hline
\end{tabular}


Table 2 Content gaps identified in search requests (continued)

\begin{tabular}{|c|c|c|c|c|c|c|}
\hline $\begin{array}{l}\text { Treatment } \\
\text { decisions: brain } \\
\text { cancer }\end{array}$ & $\begin{array}{l}\text { Temodar/radiation vs. } \\
\mathrm{PCV} / \text { radiation }\end{array}$ & 1 & $x$ & & & \\
\hline $\begin{array}{l}\text { Treatment } \\
\text { decisions: kidney } \\
\text { cancer }\end{array}$ & Partial vs. radical nephrectomy & 1 & $x$ & & & \\
\hline $\begin{array}{l}\text { Access to clinical } \\
\text { trials }\end{array}$ & Drug manufacturers & 1 & $x$ & & & \\
\hline \multicolumn{7}{|c|}{ Understanding disease prognosis } \\
\hline \multirow{4}{*}{$\begin{array}{l}\text { Survival statistics } \\
\text { and evidence }\end{array}$} & Chances and signs of recurrence & 5 & $x$ & & & \\
\hline & Age-related survival & 3 & & & & $x$ \\
\hline & $\begin{array}{l}\text { Treatment-related survival and } \\
\text { quality-of-life }\end{array}$ & 8 & & & & $x$ \\
\hline & $\begin{array}{l}\text { Risk of developing secondary } \\
\text { conditions (e.g., diabetes due to } \\
\text { prednisone) }\end{array}$ & 1 & & & & $x$ \\
\hline \multirow[t]{2}{*}{ Metastasis } & Chances of metastasis & 8 & & & & $x$ \\
\hline & Secondary cancers & 3 & & & & $x$ \\
\hline \multicolumn{7}{|c|}{ Support during and after treatment } \\
\hline \multirow[t]{3}{*}{ Support resources } & $\begin{array}{l}\text { Support groups (e.g., locations, } \\
\text { types of groups) }\end{array}$ & 5 & & & $x$ & \\
\hline & Podcasts & 1 & $x$ & & & \\
\hline & Inpatient programs & 1 & & & $x$ & \\
\hline $\begin{array}{l}\text { Health and } \\
\text { wellness }\end{array}$ & Memory improvement strategies & 1 & $x$ & & & \\
\hline \multicolumn{7}{|c|}{$\begin{array}{l}\text { Natural health products and therapeutic effects in } \\
\text { oncology }\end{array}$} \\
\hline $\begin{array}{l}\text { Antioxidants and } \\
\text { drug interactions }\end{array}$ & $\begin{array}{l}\text { Anti-angiogenesis (e.g., turmeric, } \\
\text { flax) }\end{array}$ & 1 & $x$ & $x$ & & \\
\hline \multirow{7}{*}{$\begin{array}{l}\text { Therapeutic } \\
\text { effects and access }\end{array}$} & Ganoderma (i.e., fungal medicine) & 1 & $x$ & $x$ & & \\
\hline & Cannabis (e.g., pancreatic cancer) & 6 & $x$ & $x$ & & \\
\hline & Red reishi mushroom & 1 & $x$ & $x$ & & \\
\hline & Vitamin C & 2 & $x$ & $x$ & & \\
\hline & Thermal therapy & 1 & $x$ & $x$ & & \\
\hline & Mistletoe treatment & 2 & $x$ & $x$ & & \\
\hline & Oxygen therapy & 1 & $x$ & $x$ & & \\
\hline \multicolumn{7}{|c|}{ Queries for latest research evidence from the literature } \\
\hline \multirow{6}{*}{$\begin{array}{l}\text { Effectiveness of } \\
\text { chemotherapy } \\
\text { drugs for breast } \\
\text { cancer }\end{array}$} & Paclitaxel & 1 & & $x$ & & \\
\hline & Capecitabine & 2 & & $x$ & & \\
\hline & Doxorubicin & 1 & & $x$ & & \\
\hline & Aromatase inhibitors & 1 & & $x$ & & \\
\hline & Cyclophosphamide & 1 & & $x$ & & \\
\hline & Docetaxel & 1 & & $x$ & & \\
\hline
\end{tabular}


DOI: dx.doi.org/10.5195/jmla.2021.895

Table 2 Content gaps identified in search requests (continued)

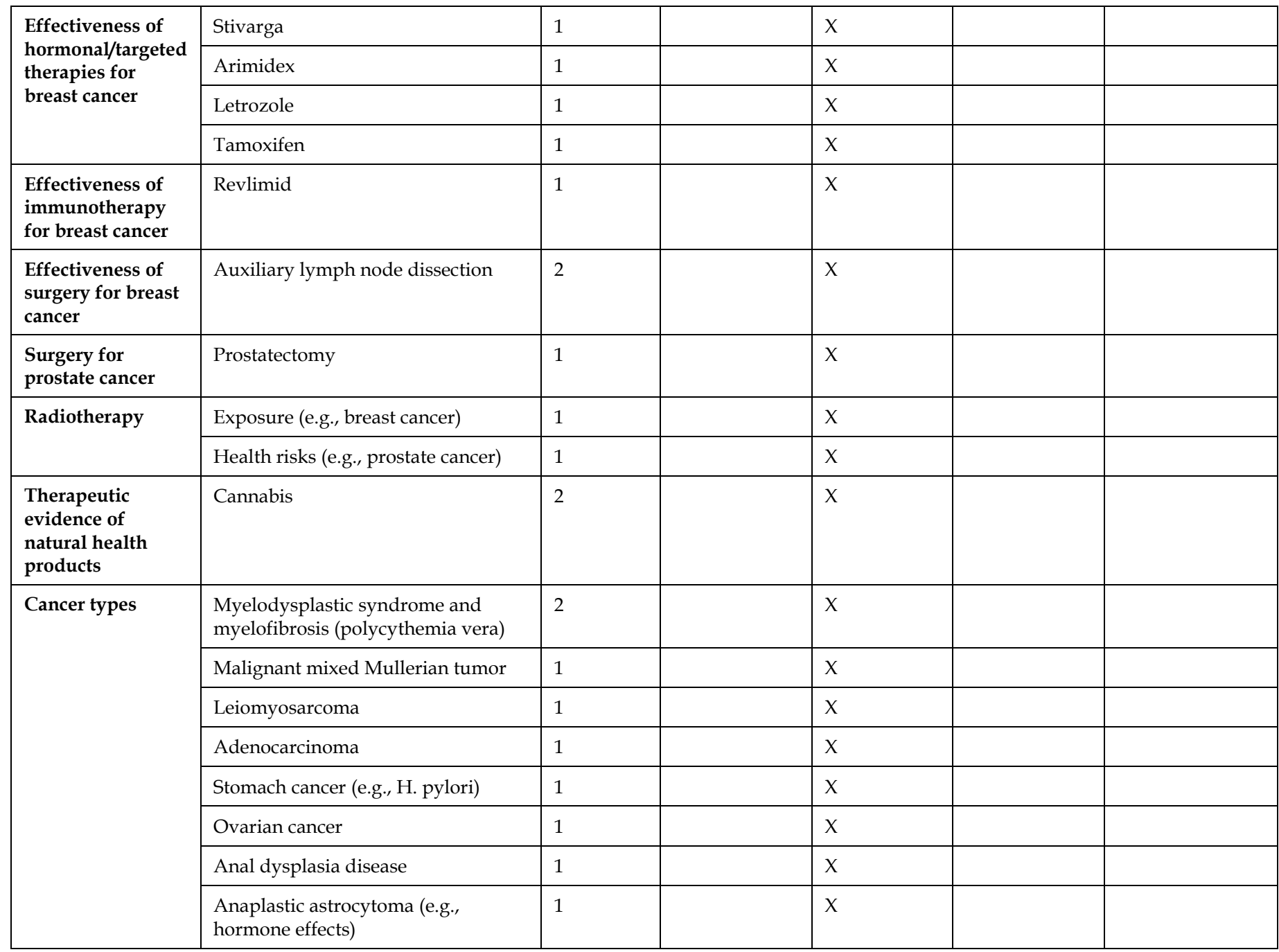

\section{DISCUSSION}

Our findings revealed that the majority of requests were submitted by cancer patients, and the most commonly requested topics were about breast cancer, with specific queries for information about advanced topics related to diagnosis, treatment, and prognosis. While the current collection contains a vast amount of information on specific types of cancer and treatments, this finding is testimony to patrons' complex information-seeking behaviors and the evolving nature of cancer and novel treatments $[5,25,26]$.

Librarians use a multitude of approaches to evaluating their collections and identifying gaps. Although traditional collection evaluation tools, such as interlibrary loan statistics or library cataloging [27], continue to serve as important tools for collection development and gap identification, some new collection evaluation tools have begun to emerge, including demand-driven acquisition [28]. Demand-driven acquisition allows users to recommend titles directly to librarians and is facilitated by some digital library lending services like OverDrive [28]. A less technical example of demand-driven acquisition described by Leonard et al. [29] was to develop and expand a print collection to include resources for patients and families. The authors found that patients and families increasingly used the print collection, and new items were added based on consumer requests. However, with the transition to digital technology and the integration of electronic materials and acquisition of external databases in e-libraries, collection development practices continue to evolve [30,31].

Search request forms can be added to the repertoire of collection evaluation tools, as they can be used as tools to respond to patrons' information needs and to identify gaps in library collections. Search request forms serve as a conduit for direct patient feedback by eliciting details about patients' specific needs for information and, more 
broadly, provide a clearer understanding about the needs of the patient population on a larger scale. Through this service, librarians are able to quantify gaps that are identified and analyze why these gaps exist. Furthermore, search requests can be monitored over time to determine whether the query reflects a persistent and long-term need or a need that is emergent based on advances in medicine.

The literature consistently shows breast cancer patients to be avid information seekers, with information about disease and treatment being the most sought-after topics $[32,33]$. Our findings complement the literature in that we found that the majority of search requests were submitted by breast cancer patients, whose queries mainly regarded cancer diagnosis, treatments, and prognostic information [34]. One of the most significant gaps identified in our study was information pertaining to treatment decisions among this population. As the decision-making preferences of breast cancer patients evolve throughout the course of their treatment and cancer journey $[35,36]$, one way to respond to this need and address this gap may be to engage clinician subject matter experts to develop resources that present the advantages and disadvantages of common treatment options for various breast cancer diagnoses.

We found that while the majority of resources provided to patrons were from the library's collection (74\%), $23 \%$ of materials provided to patrons were published research articles, and $8 \%$ of all search requests contained queries that specifically requested information from the research literature. This finding supports previous findings that as more time passes after a cancer diagnosis, patients can become more interested in the most up-to-date or current research [37]. However, this information may be difficult for patients to access due to paywalls and membership restrictions. With the increasing number of open access journals, access to this information may be less of an issue in the future. Additionally, a number of external websites were consulted to respond to patrons' queries. One study by Fulda et al. found that websites used by hospital and library websites were reliable and contributed to the library's expanding collection [38].

Furthermore, advancements in naturopathic medicine and the use of natural health products as an adjunct to conventional medicine in oncology has led to a greater demand for patient education resources. As such, libraries may wish to consider subscribing to, or purchasing licenses for, centralized digital natural health databases such as the Natural Medicines database [39] as a strategy for addressing patrons' needs for this information [40].

Not surprisingly, a significant gap identified in our study was a lack of resources on rare cancers, such as sarcomas. Patients and families dealing with rare cancers often experience a number of issues including alienation, anxiety, and worry due to fears that health care providers have limited understanding about their disease, lack of information about appropriate treatment, and limited evidence to help with decision-making processes [41]. This may in turn negatively impact communication between patients and their doctors [42], which may leave patients feeling unsupported [43]. However, the challenge in responding to requests about rare cancers lies in the fact that there is a dearth of literature and consumer health information on this topic [42]. As such, cancer centers may need to develop these patient education materials inhouse to fill this gap.

This finding points to an opportunity for librarians and patient educators to connect with clinical teams and patient education programs at other cancer centers and hospitals to determine whether they have begun to develop resources to address the same gaps. Leveraging existing resources will not only allow for timely provision of information and closing of existing collection gaps but could reduce duplicated efforts across centers and costs for patient education resource development. Our previous study reports that cancer centers spend significant amounts of time and money on patient education material development and that patient education programs could reduce some of these costs if they share resources developed by one another $[44,45]$. As such, connecting with patient education programs and libraries in other cancer centers may help librarians quickly address collection gaps.

In a small proportion of gaps, we identified that consumer health information did not meet health literacy best practices. This was the case for cancer prognostic information, including survival statistics, metastasis, and quality of life. Although cancer patients and families actively seek information on survival statistics and disease progression $[46,47]$, the vast majority of patient education materials have reading grade levels well above the recommended targets [48-50]. Furthermore, cancer patient education materials frequently fall below the acceptable standards for understandability and actionability $[48,50]$. This can have significant implications for cancer patients [51], including confusion, inability to be involved in treatment decisions, issues related to goal planning and prioritization, or decline in self-management behaviors $[52,53]$. One strategy to address this gap may be for consumer health librarians to act as advocates for healthliterate consumer health practices and provide feedback to organizations to raise awareness. Additionally, plain language assessments can be done using a number of different validated tools, including readability calculators $[54,55]$ and the Patient Education Materials Assessment Tool [56], which may be used to evaluate understandability and actionability of resources.

This study employed a retrospective review of data. In the context of cancer, advances in medical treatments happen at a quick pace and, as such, a limitation of this 
study is the issue of temporality, as a request made in 2013 may not be relevant in 2020 .

In conclusion, search request forms are a useful resource to explore gaps in consumer health libraries collections. Specifically, search request forms can be used to identify content gaps and develop an understanding of why the gaps exist, which can inform future collection development initiatives.

\section{DATA AVAILABILITY STATEMENT}

Data associated with this article cannot be made publicly available because they contain personally identifiable information. Access to data can be requested from the corresponding author at janet.papadakos@uhnresearch.ca and may be subject to Institutional Review Board restrictions.

\section{REFERENCES}

1. Sze J, Marisette S, Williams D, Nyhof-Young J, Crooks D, Husain A, Bezjak A, Wong RK. Decision making in palliative radiation therapy: reframing hope in caregivers and patients with brain metastases. Support Care Cancer. 2006 Oct;14(10):1055-63. DOI: https:// doi.org/10.1007/s00520006-0032-y.

2. Hsien JWK, Rosewall T, Wong RKS. In their own words: a qualitative descriptive study of patient and caregiver perspectives on follow-up care after palliative radiotherapy. J Med Imaging Radiat Sci. 2013 Dec;44(4):209-13. DOI: https://doi.org/10.1016/i.jmir.2013.01.001.

3. Papadakos J, Trang A, Cyr AB, Abdelmutti N, Giuliani ME, Snow M, McCurdie T, Pulandiran M, Urowitz S, Wiljer D, Deconstructing cancer patient information seeking in a consumer health library toward developing a virtual information consult for cancer patients and their caregivers: a qualitative, instrumental case study. JMIR Cancer. 2017 May;3(1):e6. DOI: https://doi.org/10.2196/cancer.6933.

4. Hesse BW, Arora NK, Burke Beckjord E, Finney Rutten LJ. Information support for cancer survivors. Cancer. 2008 Jun:112(11 Suppl):2529-40. DOI: https://doi.org/10.1002/cncr.23445.

5. Roach AR, Lykins EL, Gochett CG, Brechting EH, Graue LO, Andrykowski MA. Differences in cancer informationseeking behavior, preferences, and awareness between cancer survivors and healthy controls: a national, population-based survey. J Cancer Educ. 2009;24(1):73-79. DOI: https://doi.org/10.1080/08858190802664784.

6. Mayer DK, Terrin NC, Kreps GL, Menon U, McCance K, Parsons SK, Mooney KH. Cancer survivors information seeking behaviors: a comparison of survivors who do and do not seek information about cancer. Patient Educ Couns. 2007 Mar:65(3):342-50. DOI: https://doi.org/10.1016/j.pec.2006.08.015.

7. Rutten LJ, Arora NK, Bakos AD, Aziz N, Rowland J. Information needs and sources of information among cancer patients: a systematic review of research (1980-2003). Patient Educ Couns. 2005 Jun;57(3):250-61. DOI: https://doi.org/10.1016/j.pec.2004.06.006.
8. Rothstein JA. Ethics and the role of the medical librarian: health care information and the new consumer. Bull Med Libr Assoc. 1993 Jul;81(3):253-8.

9. Egeland M. Hospital librarians: from consumer health to patient education and beyond. J Hosp Librariansh. 2015 Feb;15(1):65-76. DOI: https://doi.org/10.1080/15323269.2015.982944.

10. Weightman AL, Williamson J, Library and Knowledge Development Network Quality and Statistics Group. The value and impact of information provided through library services for patient care: a systematic review. Health Info Libr J. 2005 Mar;22(1):4-25. DOI: https://doi.org/10.1111/j.1471-1842.2005.00549.x.

11. Marshall JG, Sollenberger J, Easterby-Gannett S, Morgan LK, Klem ML, Cavanaugh SK, Oliver KB, Thompson CA, Romanosky N, Hunter S. The value of library and information services in patient care: results of a multisite study. J Med Libr Assoc. 2013 Jan;101(1):38-46. DOI: https://doi.org/10.3163/1536-5050.101.1.007.

12. Burton JE. The impact of medical libraries and literature on patient care in New Zealand. Bull Med Libr Assoc. 1995 Oct;83(4):425-30.

13.Stacey D, Paquet L, Samant R. Exploring cancer treatment decision-making by patients: a descriptive study. Curr Oncol. 2010 Aug;17(4):85-93. DOI: https://doi.org/10.3747/co.v17i4.527.

14.Sium A, Giuliani M, Papadakos J. The persistence of the pamphlet: on the continued relevance of the health information pamphlet in the digital age. J Cancer Educ. 2017 Sept;32(3):483-6. DOI: https://doi.org/10.1007/s13187-0150948-3.

15. Cline RJ, Haynes, KM. Consumer health information seeking on the Internet: the state of the art. Health Educ Res. 2001 Dec;16(6):671-92. DOI: https:// doi.org/10.1093/her/16.6.671.

16. Bayrer R, Beattie S, Lucas E, Melberg D, Melton E. What have we done for you lately? Measuring hospital libraries' contribution to care quality. J Hosp Librariansh. 2014 Jul;14(3):243-9. DOI: https:// doi.org/10.1080/15323269.2014.888514.

17.Zipperer L. Clinicians, librarians and patient safety: opportunities for partnership. Quality and Safety in Health Care. 2004;13(3):218. DOI: https:// doi.org/10.1136/qshc.2002.003103.

18. Princess Margaret Cancer Centre. General Cancer Websites [Internet]. 2017 [cited 2019 Mar]. Available from: https://www.uhn.ca/PatientsFamilies/Health_Information /Health_Topics/Documents/General_Cancer_Websites.pdf.

19. Microsoft Corporation. Microsoft Excel. 2018.

20.Thomas DR. A general inductive approach for analyzing qualitative evaluation data. Am J Eval. 2006;27(2):237-46. DOI: https:// doi.org/10.1177/1098214005283748.

21. Vaismoradi M, Turunen $\mathrm{H}$, Bondas T. Content analysis and thematic analysis: implications for conducting a qualitative descriptive study. Nurs Health Sci. 2013:15(3):398-405. DOI: https://doi.org/10.1111/nhs.12048. 
22. Centers for Disease Control and Prevention. Health literacy: develop \& test materials [Internet]. 2019. Available from: https://www.cdc.gov/healthliteracy/developmaterials/ind ex.html.

23. American Society of Clinical Oncology. 2021. Available from: https://www.asco.org/.

24. Kue J, Klemanski DL, Browning KK. Evaluating readability scores of treatment summaries and cancer survivorship care plans. JCO Oncol Pract. 2021 Feb;OP.20.00789. DOI: https://doi.org/10.1200/op.20.00789.

25.Shim EJ, Park JE, Yi M, Jung D, Lee KM, Hahm BJ. Tailoring communications to the evolving needs of patients throughout the cancer care trajectory: a qualitative exploration with breast cancer patients. BMC Womens Health. 2016 Oct;16(1):65. DOI: https:// doi.org/10.1186/s12905-016-0347-x.

26. Germeni E, Bianchi M, Valcarenghi D, Schulz PJ. Longitudinal qualitative exploration of cancer informationseeking experiences across the disease trajectory: the INFOSEEK protocol. BMJ Open. 2015 Oct;5(10):e008933. DOI: https://doi.org/10.1136/bmjopen-2015-008933.

27. Johnson Q. Mind the gap: using patron actions to identify holes in a library's collection. In: 2016 Library Assessment Conference. Northwestern University; 2016.

28. Levenson HN. Notes on operations nimble: collection development policies. Libr Resour Tech Serv. 2019:63(4).

29. Leonard K, Earl M. Health information without limits: a print collection for consumers in the heart of the hospital. J Hosp Librariansh. 2016;16(2):132-44. DOI: https://doi.org/10.1080/15323269.2016.1150739.

30. Corrall S. Part 1: The concept of collection development in the digital world. Collection Development in the Digital Age. Cambridge University Press. 2011. DOI: https://doi.org/10.29085/9781856048972.003.

31.Samantaray Rath M, Rath P. Collection development in libraries: challenges and solutions for library professionals. Pearl: A Journal of Library and Information Science. 2014; 8:53. DOI: https://doi.org/10.5958/j.0975-6922.8.1.009.

32. Eheman CR, Berkowitz Z, Lee J, Mohile S, Purnell J, Rodriguez EM, Roscoe J, Johnson D, Kirshner J, Morrow G. Information-seeking styles among cancer patients before and after treatment by demographics and use of information sources. J Health Commun. 2009 Jul-Aug;14(5):487-502. DOI: https://doi.org/10.1080/10810730903032945.

33. Kimiafar K, Sarbaz M, Shahid Sales S, Esmaeili M, Javame Ghazvini Z. Breast cancer patients' information needs and information-seeking behavior in a developing country. The Breast. 2016;28:156-60. DOI https://doi.org/10.1016/j.breast.2016.05.011.

34. McLellan F. "Like hunger, like thirst": patients, journals, and the internet. Lancet. 1998;352(Suppl 2):SII39-43.

35. Berger O, Gronberg BH, Loge JH, Kaasa S, Sand K. Cancer patients' knowledge about their disease and treatment before, during and after treatment: a prospective, longitudinal study. BMC Cancer. 2018 Apr;18(1):381. DOI: https:// doi.org/10.1186/s12885-018-4164-5.
36. Vogel BA, Bengel J, Helmes AW. Information and decision making: patients' needs and experiences in the course of breast cancer treatment. Patient Educ Couns. 2008;71(1):79_ 85. DOI: https:// doi.org/10.1016/j.pec.2007.11.023.

37. Quality Health. National Cancer Patient Experience Survey 2014 National Report. 2014. England. Available from: https://www.lcnuk.org/system/files/English_cancer_expe rience_survey_2014.pdf.

38. Fulda PO, Kwasik H. Consumer health information provided by library and hospital Websites in the South Central Region. J Med Libr Assoc. 2004;92(3):372-5.

39. Natural Medicines. Natural medicines \& Supplements Database [Internet]. 2021. Available from: https://trchealthcare.com/about-us/products/naturalmedicines/.

40.Scarton LA, Del Fiol G, Oakley-Girvan I, Gibson B, Logan R, Workman TE. Understanding cancer survivors' information needs and information-seeking behaviors for complementary and alternative medicine from short- to long-term survival: a mixed-methods study. J Med Libr Assoc. 2018;106(1):87-97. DOI: https://doi.org/10.5195/jmla.2018.200.

41. Loggers ET, Prigerson HG. The end-of-life experience of patients with rare cancers and their caregivers. Rare Tumors. 2014 Jan;6(1):5281. DOI: https://doi.org/10.4081/rt.2014.5281.

42. Bell C, Kerr K, Moore K, McShane C, Anderson L, McKnight $\mathrm{AJ}$, McAneney H. Communication strategies for rare cancers: a systematic review protocol. Syst Rev. 2019 Apr;8(1):102. DOI: https:// doi.org/10.1186/s13643-019-1017-5.

43. Fitch MI. Needs of patients living with advanced disease. Can Oncol Nurs J. 2005 Autumn; 15(4):230-42. DOI: https://doi.org/10.5737/1181912x154230235.

44.Papadakos J, Giannopoulos E, Forbes L, Fox C, Jain P, McBain S, Mittman N, Moody L, Samoil D, McLeod R. Reinventing the wheel: the incidence and cost implication of duplication of effort in patient education materials development. Patient Educ Counsel. 2021;104(6):1398-1405. DOI: https:// doi.org/10.1016/i.pec.2020.11.017.

45.Papadakos J, Samoil D, Giannopoulos E, Jain P, McBain S, Mittmann N, Papadakos T, Fox C, Moody L, McLeod R. The cost of patient education materials development: opportunities to identify value and priorities. J Cancer Educ. 2020. DOI: https:// doi.org/10.1007/s13187-020-01893-0.

46. Ghazavi-Khorasgani Z, Ashrafi-Rizi H, Mokarian F, Afshar $M$. Health information seeking behavior of female breast cancer patients. J Educ Health Promot. 2018;7: 138. DOI: https://doi.org/10.4103/jehp.jehp_17 18.

47.Solowski NL,Okuyemi OT, Kallogjeri D, Nicklaus J, Piccirillo JF., Patient and physician views on providing cancer patient-specific survival information. Laryngoscope. 2014;124(2):429-35. DOI: https://doi.org/10.1002/lary.24007.

48. Charow R, Snow M, Fathima S, Giuliani ME, McEwan K, Winegust J, Papadakos J. Evaluation of the scope, quality, and health literacy demand of Internet-based anal cancer information. J Med Libr Assoc. 2019;107(4):527-37. DOI: https://doi.org/10.5195/jmla.2019.393. 
49. Rooney MK, Sachdev S, Byun J, Jagsi R, Golden DW. Readability of patient education materials in radiation oncology-are we improving? Pract Radiat Oncol, 2019;9(6):435-40. DOI: https://doi.org/10.1016/i.prro.2019.06.005.

50.Papadakos JK, Giannopoulos E, McBain S, Forbes L, Jain P, Samoil D, Wang J, Zwicker V, Fox C, Moody L, McLeod R. Quality assessment of cancer patient education materials: the current state of systemic therapy patient education in fourteen cancer centres across Ontario, Canada. Support Care Cancer. 2020. DOI: https:// doi.org/10.1007/s00520020-05859-2.

51. Foltz AT, Sullivan JM. Limited literacy revisited implications for patient education. Cancer Pract. 1999;7(3):145-50. DOI: https:// doi.org/10.1046/j.1523-5394.1999.07304.x.

52. Van Dijck S, Nelissen P, Verbelen H, Tjalma W, Gebruers N. The effects of physical self-management on quality of life in breast cancer patients: a systematic review. Breast. 2016;28:20-28. DOI: https://doi.org/10.1016/j.breast.2016.04.010.

53. Ghandourh WA. Palliative care in cancer: managing patients' expectations. J Med Radiat Sci. 2016;63(4):242-57. DOI: https://doi.org/10.1002/jmrs.188.

54. Fry E. Fry's readability graph: clarifications, validity and extension to level 17. The Journal of Reading. 1977.

55. Mclaughlin G. SMOG grading - a new readability formula. The Journal of Reading. 1969

56. Agency for Healthcare Research and Quality. PEMAT for Printable Materials (PEMAT-P). Rockville, MD; 2020. Available from: https://www.ahrq.gov/healthliteracy/patient-education/pemat-p.html.

\section{AUTHORS' AFFILIATIONS}

Eleni Giannopoulos, eleni.giannopoulos@uhnresearch.ca, Research Analyst, Cancer Health Literacy Research Centre, Cancer Education, Princess Margaret Cancer Centre, Toronto, Ontario, Canada

Michelle Snow, michelle.snow@uhn.ca, Librarian, Princess Margaret Cancer Centre, Toronto, Ontario, Canada

Mollie Manley, mollie.manley@gmail.com, Princess Margaret Cancer Centre, Toronto, Ontario, Canada

Katie McEwan, highlandkate@sympatico.ca, Princess Margaret Cancer Centre, Toronto, Ontario, Canada

Andrew Stechkevich, andrew.stechkevich@uhnresearch.ca, Cancer Health Literacy Research Centre, Cancer Education, Princess Margaret Cancer Centre, Toronto, Ontario, Canada

Meredith Elana Giuliani, meredith.giuliani@rmp.uhn.on.ca, Radiation Oncologist, Medical Director Cancer Education, Princess Margaret Cancer Centre, Toronto, Ontario, Canada

Janet Papadakos, janet.papadakos@uhnresearch.ca, https://orcid.org/0000-0001-6320-4156, Codirector, Cancer Health Literacy Research Centre, Cancer Education, Princess Margaret Cancer Centre; Provincial Head, Patient Education Cancer Care Ontario; Assistant Professor, University of Toronto, Toronto, Ontario, Canada

Received November 2019; accepted June 2021

\section{(c) (i) \\ ULS} Articles in this journal are licensed under a Creative Commons Attribution 4.0 International License. This journal is published by the University Library System of the University of Pittsburgh as part of its D-Scribe Digital Publishing Program and is cosponsored by the University of Pittsburgh Press. 